\title{
OUR AIMS AND OUR IDEALS
}

A NEGLECT as reprehensible as it was stigmatic characterised the attitude of a large proportion of the medical profession towards venereal disease until the earlier years of this century.

Since 1907 considerable laboratory and clinical work has been directed towards the scientific diagnosis and treatment of this group of diseases. But, as the years passed by, no successful attempt was made, by means of a corporate alliance, in this country at least, to develop, co-ordinate and focus the interest and the efforts of medical practitioners responsible for these increased activities.

In June, I922, the Medical Society for the Study of Venereal Diseases was founded. From the beginning it was felt that, if its beneficent potentialities were to be realised, it would be necessary to appeal, and that through a literary medium, to a larger body of practitioners than those who were able to attend the meetings of the parent Society in London, or of the Scottish branch in Edinburgh or Glasgow. Economic and other difficulties which blocked the way have been overcome, and with this January number, the British Journal of Venereal Diseases begins a life which must, and will be, energetic and stimulating.

We see before us a large and increasing number of workers who are devoting themselves to the study of venereal disease, and we know that the attitude of many, as regards this Journal, is one of critical expectancy. Their corporate thought resolves itself into the question "Of what intellectual and material use will this Journal be to us?"

We answer that the Journal will enable the worker in venereal diseases to keep abreast with progress, in his own and allied subjects, by placing before him such data as are necessary to the achievement of this end. Of the original articles which it will publish, some will appeal essentially to the specialist, either in the laboratory or in the clinic, whilst others will aim to help the general 


\section{BRITISH JOURNAL OF VENEREAL DISEASES}

practitioner in the study of venereal disease, to whom this work is but one of many tasks.

It will be our duty to see that these articles are rendered valuable because of the information and the opinions which they put forward, and because of their energising effect upon our readers. Every article will, as far as is possible, be accompanied by a bibliography calculated to help the student who wishes to investigate the subject more deeply or more comprehensively.

Critical reviews will be published regularly, and will deal with the world's periodical literature on syphilis, gonorrhœa and allied subjects. We attach the greatest importance to the fact that these will be not merely notices of, but full, critical and informative reviews of articles in other journals, the value of which demands that they should be brought to the notice of our readers. Searching and elucidatory criticisms of new books will also be forthcoming.

The nature of the articles and their correlated presentation in this Journal will be in consonance with and conducive to the development of that scientific attitude which must be attained by the worker in the laboratory and the clinician if progress is to be the result of their reciprocal activities.

In order to achieve and maintain this standard, we shall exercise a stringent, impartial and judicial selective power in respect to the contents of our columns. We would here, in anticipation of our hardest task, point out that at times we may be called upon to damp an empiric enthusiasm (that offspring of inexperience and sensationalism) when this would advocate measures, or leap to conclusions, unjustified by existent data. At such times, oblivious of popular opinion, we shall not hesitate to assume a position of agnosticism, in the true Huxleyan sense of the word, and thereby ultimately serve the deepest interests of the public and of our readers.

If the laboratory worker on the one hand, and the clinician on the other, desires to possess an outlook and to engender results of the fullest scientific value, it follows that there must be a complementary alliance of correlated theory and endeavour between these workers.

The possession of such a scientific outlook and of energetic enthusiasm will be of little avail unless there is the fullest, keenest and most sincere co-operation amongst all 


\section{BRITISH JOURNAL OF VENEREAL DISEASES}

workers in the important field of research and achievement in which they labour. As our readers will not look to us in vain for the assistance which they can reasonably demand, so do we rely on them to extend to us their help and their encouragement, their wise, suggestive counsel and their judicial criticism. We would ask them to realise that when a new Journal appears its gait may halt, the result of a necessary spirit of caution and of a desire to develop along lines most calculated to secure the interest of its readers.

To our fellow-workers in other lands we send the message that the literary fields in which we would reap will for us possess no limits. We ask them for their contributions in the shape of articles and of news, and, in asking, we know that we shall have their co-operation.

By the collection and the emission of the soundest data, by the scientific manipulation and presentation of such data, and by the development of the truest spirit of cooperation, we intend to help those for whom the Journal will exist. In order that we may materialise our ideals, energy, both dynamic and potential, is a necessity. This energy must be exercised by ourselves and by our readers, and it behoves both us and them to see to it that this energy and its resultant knowledge shall be communicated to others, who, in their turn, will hand on the torch of progress. If we succeed, not only will the cause of pure science be advanced, but the suffering and the inefficiency which through venereal disease is in the world will some day cease to be.

The British Journal of Venereal Diseases is published under the direction of the Council of the Medical Society for the Study of Venereal Diseases, and is conducted by an Editorial Committee elected by the Council.

Editorial communications should be sent to the Editors, 43, Queen Anne Street, London, W. I.

The Journal is published quarterly, January, April, July and October. The subscription is 20s. per annum (post free) ; single numbers, $6 s$. net each.

Orders for the Journal and communications regarding advertisements should be addressed to the publishers, Messrs. Constable \& Co., Io and I2, Orange Street, London, W.C. 2. 


\section{BRITISH JOURNAL OF VENEREAL DISEASES}

\section{THE MEDICAL SOCIETY FOR THE STUDY OF VENEREAL DISEASES.}

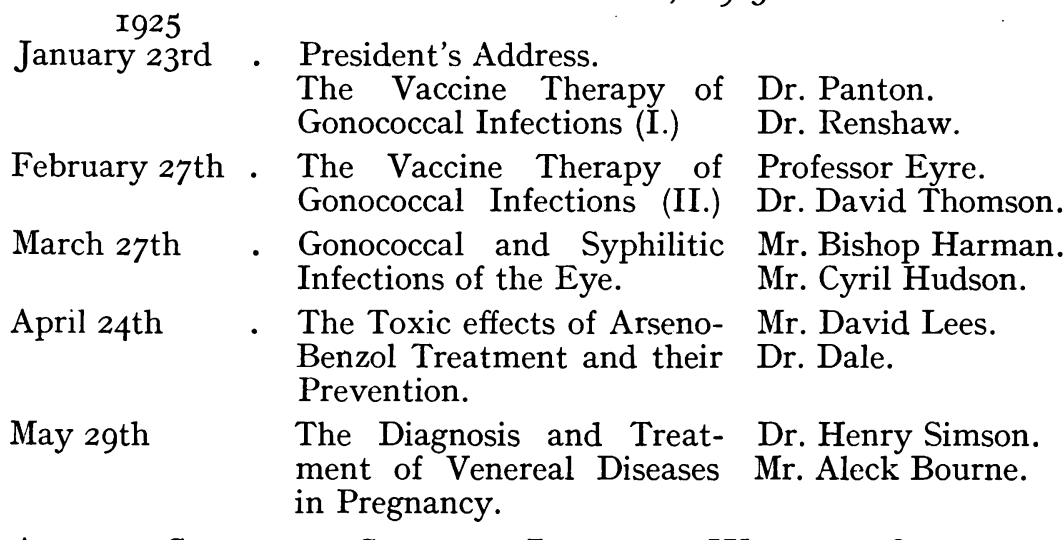

At it, Chandos Street, London, W.I, at 8.30 P.M. 